\title{
Superior Sulcus Lung Carcinoma
}

National Cancer Institute

\section{Source}

National Cancer Institute. Superior Sulcus Lung Carcinoma. NCI Thesaurus. Code C7779.

A carcinoma originating from the apical lung. Most superior sulcus lung carcinomas are bronchogenic carcinomas. This carcinoma may be associated with Pancoast syndrome. It is also known as Pancoast tumor. 